\title{
La bibliotecaria Luisa Cuesta Gutiérrez (1892-1962)
}

\author{
Pilar EgOSCOZÁBAL CARRASCO \\ Biblioteca Nacional. Servicio de Reserva Impresa \\ pilar.egoscozabal@bne.es \\ María Luisa MediaviLla HerReros \\ Biblioteca de Mujeres \\ bibliomujer@gmail.com
}

Recibido: Septiembre 2011

Aceptado: Julio 2012

Resumen: Luisa Cuesta Gutiérrez, miembro del Cuerpo Facultativo de Archiveros, Bibliotecarios y Arqueólogos, fue un ejemplo de mujer moderna que se enfrentó a las condiciones socioeconómicas de la mujer de principios de siglo para protagonizar una brillante carrera como docente, investigadora y, sobre todo, bibliotecaria, centrándose su actividad en la Biblioteca Nacional. Desempeñó un papel activo durante la Guerra Civil como miembro de la Comisión Gestora del Cuerpo Facultativo y fue depurada al acabar aquella. Se analizan su trayectoria biográfica y profesional, reflejada en una obra bibliográfica importante que abarca diversos temas, desde la investigación histórica al feminismo, y centrada, en su última etapa, en la historia de la imprenta. En este sentido, destaca la elaboración de dos tipobibliografías posteriormente completadas: La imprenta en Salamanca y La imprenta en Burgos.

Palabras clave: Luisa Cuesta Gutiérrez, Guerra Civil Española; Cuerpo Facultativo de Archiveros; Bibliotecarios y Arqueólogos; Depuración de funcionarios; Biblioteca Nacional de España.

\section{The librarian Luisa Cuesta Gutiérrez (1892-1962)}

\begin{abstract}
Luisa Cuesta Gutiérrez, a member of the High Council of Civil Archivists, Librarians and Archaeologists, was a model of modern woman who fought against the socioeconomic conditions in the beginning of the XX century to develop a brilliant career as a teacher, researcher and especially as a librarian, working at National Library. She played an active role during the Spanish Civil War as a member of the Interim Committee of the High Council and she was purged when the war finished. Her biographical and professional profiles are shown, the second one expressed in a significant bibliographical work covering different subjects, from historical research to feminism, and focused, in her final stage, on printing history. In this sense, the elaboration of two bibliographies which were later completed: Printing in Salamanca and Printing in Burgos, is outstanding.
\end{abstract}

Keywords: Luisa Cuesta Gutiérrez; Spanish Civil War; High Council of Civil of Archivists; Librarians and Archaeologists; Civil servants' purge; National Library of Spain. 


\section{INTRODUCCIÓN}

Quienes trabajamos en bibliotecas tenemos que agradecer la labor que realizaron en 2005 Ramón Salaberría y Blanca Calvo, plasmada en la exposición "Biblioteca en guerra", que pudimos disfrutar en la Biblioteca Nacional entre el 15 de noviembre y el 19 de febrero. La exposición, su catálogo, sus imágenes, han quedado grabadas para siempre en nuestra memoria, esa memoria que tiene que luchar contra el olvido que denunciaba una derrotada Teresa Andrés. Y del olvido tenemos que seguir sacando a quienes lucharon por nuestro patrimonio bibliográfico desde la dignidad que les caracterizó y que se les quiso hacer perder una vez finalizada la guerra. Depuraciones, traslados forzosos, interrupción de unas carreras profesionales que contaban con una base y un trabajo de años... En la revista Educación y Biblioteca se ha tratado ampliamente de algunas de estas personas: Juan Vicens, Teresa Andrés y María Moliner' ${ }^{1}$ La bibliotecaria de la Universidad Complutense Juana Capdevielle, por otra parte, es objeto de una monografía escrita recientemente por Cristina Gállego Rubio ${ }^{2}$. Nosotras nos proponemos, siguiendo la misma línea, rescatar a una de aquellas bibliotecarias que padeció las consecuencias nefastas de una represión marcada por el revanchismo y la miseria moral.

\section{DE CÓMO UNA NIÑA DE MEDINA DE RIOSECO LLEGÓ A DOCTORARSE EN FILOSOFÍA Y LETRAS Y DERECHO, A PESAR DE SER MUJER A COMIENZOS DEL SIGLO XX}

Luisa Cuesta Gutiérrez nació en Medina de Rioseco (Valladolid) el 19 de agosto de 1892, hija, como podemos leer en su partida de nacimiento, de un sobrestante o capataz y de una mujer dedicada "a las labores propias de su sexo"".

\footnotetext{
${ }^{1}$ En los números 108 (2000), 145 (2005) y 175 (2010), respectivamente.

${ }^{2}$ Juana Capdevielle San Martín, bibliotecaria de la Universidad Central. Madrid: Editorial Complutense, 2010.

${ }^{3}$ Para trazar la biografía de Luisa Cuesta hemos consultado la documentación contenida en los expedientes personal y de depuración, depositados en el Archivo General de la Administración de Alcalá de Henares (Cajas 31/7018 y 31/6056, respectivamente). También se han consultado, y aprovechamos estas líneas para agradecer a Enrique Pérez Boyero la ayuda prestada para la localización de estas fuentes, los expedientes de la Biblioteca Nacional y de la Junta Facultativa (BNE-A BN 2899/5 [provisional] y BNE-A Junta 230/9), así como los académicos de las universidades de Santiago (1-VIII-921, No 397), Valladolid (LIB3129-1, LIB3129-2, LIB1894, LIB2068, LIB306 y LEG681-2) y Central de Madrid (Archivo General de la UCM, EA-027,56). Asimismo, existe documentación en el archivo de la Residencia de Estudiantes (carpetas 42, 1831). La obra de Agustín Ruiz Cabriada Bio-bibliografía del Cuerpo Facultativo de Archiveros, Bibliotecarios y Arqueólogos, 1858-1958. Madrid: Junta Técnica de Archivos, Bibliotecas y Museos, 1958, ofrece datos sobre la bibliotecaria, aunque contiene
} 
Podemos imaginar la vida en un pueblo como Medina a finales del XIX, aún más si leemos en periódicos como El Financiero Hispanoamericano que el siglo XX era "como si no corriese para Rioseco". Una población marcada por el analfabetismo y por la penuria económica, por la influencia de la iglesia católica y por el tradicionalismo más cerril fue el escenario en el que creció Luisa, que pronto demostró que no estaba predestinada a seguir la trayectoria familiar. Por supuesto, ella lo tenía aún más difícil por el hecho de haber nacido mujer en una época en la que una de cada siete hombres estudiaba bachillerato.

En 1910 se examina del grado de bachiller en el Instituto de Valladolid y obtiene la calificación de sobresaliente. Precisamente ese fue el año en el que se promulgó la Real Orden que autorizaba el acceso de las mujeres a la universidad, siendo consejera de Instrucción Pública la escritora Emilia Pardo Bazán. En este punto debemos hacer un inciso para conocer, muy brevemente, los principales avances que habían tenido lugar hasta entonces en el terreno de la educación de la mujer y las principales instituciones que la favorecieron, pues con todo ello se encontró Luisa Cuesta y de todo supo sacar el mayor partido.

La lucha de las mujeres por el derecho a la educación se había visto favorecida por la labor de personas como Fernando de Castro, sacerdote, pedagogo y catedrático de Literatura en la Universidad de Madrid, que entró en contacto en 1854 con el introductor del krausismo en España, Julián Sanz del Río, inspirador de los principios en los que se basó la Institución Libre de Enseñanza. Fernando de Castro impulsó la creación del Ateneo Artístico y Literario de Madrid en 1869-70, la celebración de conferencias dirigidas a la educación de la mujer y la fundación de la Asociación para la Enseñanza de la Mujer, aunque hay que señalar que el objeto de potenciar dicha educación estaba dirigida, como fin último, a que pudieran dedicarse a la de sus hijos. Sin embargo, será el germen de las ideas educativas de Giner de los Ríos, Gumersindo de Azcárate y otros, que cristalizarán en la Institución Libre de Enseñanza, cuyo funcionamiento comienza en 1876.

algunos errores, así como la página web Cultura Galega.org: http://www. culturagalega.org/album/detalle.php. Puede prestarse a confusión la consideración que se hace de la bibliotecaria como "A última directora republicana da Biblioteca Nacional" pues, como veremos en este artículo, nunca ocupó tal cargo, limitándose a asumir la responsabilidad en funciones durante la estancia del entonces director, Navarro Tomás, en Valencia y durante un corto periodo de tiempo. Breves referencias encontramos también en el artículo de Rosa San Segundo Manuel "Mujeres bibliotecarias durante la Segunda República Española: de vanguardia intelectual a depuración", http:/www.educacion.es/cesces/ revista/extr2010sansegundo-manuel.pdf (aunque cambia el segundo apellido por "Rodríguez") y en Biblioteca en guerra [catálogo de la exposición]. Madrid: Biblioteca Nacional, 2005, p. 247. 
Es de destacar igualmente la labor de la Junta de Ampliación de Estudios, creada en 1907 y dirigida por José Castillejo, que gestionó diversas instituciones sin discriminar, antes bien, favoreciendo, a las mujeres.

En 1915 comenzó a funcionar la Residencia de Señoritas, a los cinco años de haberse creado la Residencia de Estudiantes y después del traslado de los varones de la calle Fortuny a la del Pinar. Su dirección se encomendó a María de Maeztu, que colaboró estrechamente con el Instituto Internacional, institución fundamental en la vida cultural de la época y sobre todo en lo relativo a la enseñanza de la mujer. Remitimos a las autoras Carmen de Zulueta, Rosa Capel y Carmen Magallón ${ }^{4}$ para la profundización en la labor de estas instituciones, pero destacamos la organización de una biblioteca circulante, que se hizo eco del sistema anglosajón de bibliotecas y que se combinó con la de la Residencia, contratando a varias españolas para la organización de los catálogos. Posteriormente se ofreció un cursillo de Biblioteconomía que se amplió a dos años y cuyo objetivo era, fundamentalmente, la formación práctica. La Residencia de Señoritas contribuyó, por otra parte, a despertar en las jóvenes nuevas aspiraciones personales y profesionales. Es interesante resaltar el espíritu abierto de la institución, que daba cabida a todas aquellas mujeres autodidactas que, por iniciativa propia, deseaban perfeccionarse estudiando fuera de los ámbitos oficiales. Todas estas instituciones las conoció de cerca Luisa Cuesta, e incluso mantuvo una estrecha relación con la directora, María de Maeztu, y con Pura Arias y Eulalia Lapresta, bibliotecaria y secretaria de la Residencia, respectivamente.

Tras el bachillerato, Luisa Cuesta cursa los estudios de Maestra Superior en la Escuela Normal de Valladolid, graduándose con la misma nota y aprobando, con el número uno, una oposición libre en 1914, por la que fue nombrada maestra nacional de la escuela de Población de Campos (Palencia). Al mismo tiempo que ejercía el magisterio se matriculó en la entonces llamada Universidad Literaria de Valladolid para cursar los estudios de Filosofía y Letras durante el curso 1914-15. Este primer año obtuvo la calificación de sobresaliente con matrícula de honor en todas las asignaturas. Solicitó el traslado para cursar los tres años restantes a la Universidad Central de Madrid (en la Facultad de Filosofía y Letras de Valladolid solo se cursaba por entonces el primer año), traslado que le fue concedido en agosto de 1916, habiendo renunciado previamente al puesto de maestra.

\footnotetext{
${ }^{4}$ ZULUETA, Carmen de: Cien años de educación de la mujer española: historia del Instituto Internacional. Madrid: Castalia, 1992; MAGALlón PORTOLÉS, Carmen: "El laboratorio Foster de la Residencia de Señoritas. Las relaciones de la JAE con el International Institute for Girls in Spain y la formación de las jóvenes científicas españolas" en Asclepio. Revista de Historia de la Medicina y de la Ciencia, 2 (2007), pp. 37-62; CAPEL MARTínEZ, Rosa Mª "El archivo de la Residencia de Señoritas”, en Participación Educativa, 11 (2009), pp. 156-161.
} 
Las calificaciones obtenidas en los tres cursos fueron siempre excelentes, con la excepción de un suspenso en junio de 1917 en la asignatura Historia Universal Antigua y Media, que recupera en septiembre con matrícula de honor.

El último curso en el que Luisa se matricula en la Universidad Central, con las asignaturas de Latín (primer curso de ampliación) y Bibliología, se realizaba con carácter voluntario y estaba encaminado a favorecer a las alumnas y alumnos que aspirasen a ingresar en el Cuerpo Facultativo de Archiveros, Bibliotecarios y Arqueólogos, para lo que se necesitaba la licenciatura en la sección de Historia y haber cursado estas dos asignaturas. El 4 de enero de 1918, Luisa se dirige a María de Maeztu para solicitar una habitación en la Residencia de Señoritas en la que alojarse unos 12 o 14 días, ya que se tiene que examinar de esas dos asignaturas. En total, tenemos documentadas catorce cartas, entre 1918 y 1925, que demuestran que existía una relación fluida entre ambas mujeres, pues hace relación a asuntos familiares que van más allá de la simple petición formal y también a aspectos de su propia vida. El mismo año, una vez aprobadas las dos asignaturas, volverá a escribirle, con fecha de 4 de julio, para solicitar habitación para el curso siguiente, en el que se dispone a hacer el doctorado. Indica además que le agradaría "explicar alguna de las clases del [Instituto] Internacional”, para lo que sin duda estaba capacitada dada su experiencia previa como maestra.

Luisa culmina sus estudios en Valladolid en 1918, realizando el último curso de especialización en la Sección de Historia y el examen de licenciatura, en el que obtuvo sobresaliente y premio extraordinario. Posteriormente realiza los cursos de doctorado en la Universidad Central, suponemos que por libre, pues por las mismas fechas estuvo trabajando como "auxiliar interino supernumerario" en Valladolid, donde solicitó el puesto al terminar la carrera, que el claustro de la Universidad de Valladolid le concedió por unanimidad. Entre 1918 y 1921 fue profesora de la Facultad de Filosofía y Letras, Sección de Historia, ejerciendo su primera vocación, la docente, que había comenzado, como hemos visto, con el magisterio en Población de Campos. A partir de ahora desarrollará también su vocación investigadora, que continuará cultivando durante el resto de su vida. Esta etapa de docencia e investigación culmina con la tesis doctoral que presenta en 1927 en la Universidad Central sobre La Gasca en América: contribución al estudio de la politica colonizadora de España en América durante el siglo XVI

\footnotetext{
${ }^{5}$ El ejemplar de la tesis figura entre los fondos de la Universidad Complutense, y está accesible a través del catálogo Cisne (T 5204). La tesis se publicó al año siguiente de su lectura: Santiago de Compostela: Tip. de El eco franciscano, 1928.
} 


\section{LOS INICIOS DE UNA CARRERA BIBLIOTECARIA: LA UNIVERSIDAD DE SANTIAGO DE COMPOSTELA Y LA BIBLIOTECA NACIONAL}

Luisa Cuesta oposita en 1920 a Enseñanza Media y obtiene una plaza en Palacios de la Sierra (Burgos), aunque no llega a incorporarse porque en 1921 aprueba las oposiciones al Cuerpo Facultativo de Archiveros, Bibliotecarios y Arqueólogos con el número 16, en una promoción que incluye a Moreno Villa con el 18 y a Juan Larrea con el 3. Inicia así su trayectoria como bibliotecaria, aunque sin dejar de lado la académica, siempre presente tanto en sus estudios como en sus publicaciones. Como podremos comprobar, Luisa Cuesta siempre fue receptiva a todo lo que le rodeó en sus diferentes puestos de trabajo, enriqueciéndose constantemente y aprovechando todas las oportunidades que se le fueron presentando y que dieron lugar a un interesante currículum.

Su primer destino fue la Universidad de Santiago de Compostela, donde toma posesión en julio de 1921. Al mismo tiempo, se matricula en la Facultad de Derecho por libre, siempre obteniendo las mismas excelentes calificaciones. Si la trayectoria académica era impecable, la profesional comenzaba a dar muestras de lo mismo: en 1923 la Facultad de Ciencias de la Universidad le otorgó un voto de gracia por los trabajos de catalogación que en unión de su jefe, José María de Bustamante y Urrutia, fueron realizados en su biblioteca.

Y de nuevo aflora su vocación por la enseñanza: ejerce como profesora auxiliar desde 1924 hasta 1930 que se traslada a Madrid. Y es que, por las mismas fechas en las que defendía su tesis en Madrid, época en la que estuvo alojada en la Residencia de Señoritas, Luisa había solicitado traslado a la Biblioteca Nacional, traslado que se resolvió favorablemente, incorporándose en octubre a su nuevo destino. Era director de la Biblioteca por aquel entonces Miguel Artigas, a quien veremos durante la guerra tomando partido a favor del bando franquista y enfrentado a Tomás Navarro Tomás en una agria polémica acerca de la protección del patrimonio bibliográfico ${ }^{6}$. Como era de esperar, Artigas volvió a ocupar la dirección de la Biblioteca una vez finalizada la guerra, mientras Navarro Tomás comenzaba una nueva vida en el exilio.

Volviendo al comienzo de la carrera profesional de Luisa Cuesta en la Biblioteca Nacional, continuó compaginando su actividad bibliotecaria (por estos años sabemos que desempeña la jefatura del Salón de Lectura) con la investigación, sin romper el hilo, en cuanto a la materia objeto de su estudio, que la unía con la Universidad de Santiago. Entre 1930 y 1935 publica: Los orígenes

\footnotetext{
${ }^{6}$ La réplica de Navarro Tomás a Artigas puede consultarse en Biblioteca en guerra, op. cit., pp. 209-225.
} 
de la Biblioteca Universitaria de Santiago 7, "La emigración gallega a América", "La Universidad de Santiago: su pasado, su presente y su porvenir" (estas dos últimas habían sido premiadas en el certamen del Centro Gallego de Montevideo de 1929 con las medallas del presidente de la República Argentina y del Rey de España Alfonso XIII, respectivamente), "La imprenta en Santiago de Compostela"10, "María Lejárraga de Martínez Sierra", en la revista Vida femenina", "Un formulario inédito de Cataluña" ${ }^{11}$, e "Incunables con grabados en la Biblioteca Nacional de Madrid" "13. Es fácil deducir que comienza finalizando trabajos que había comenzado durante su estancia en Santiago, a los que añade otros relacionados con su licenciatura en Derecho, con sus inquietudes feministas y con el material al que tenía acceso en la Biblioteca Nacional: el fondo antiguo y, concretamente, los incunables. Otra línea de investigación clara es la historia de América, cuyo interés data de su primera licenciatura en Madrid y que suponemos marcada por el auge de los estudios americanistas en la Universidad de Santiago por aquella época, representados por el Instituto de Estudios Americanistas y la Biblioteca América, de cuya gestación, por iniciativa del emigrante gallego en Buenos Aires Gumersindo Busto, tuvo que ser partícipe, o al menos testigo. Su nueva tesis en Derecho, que leerá en la Universidad Central de Madrid en 1930, trata sobre La colonización de la Patagonia en el siglo XVIII ${ }^{14}$, donde el tema americano se enfoca desde una perspectiva jurídica. En 1933 es nombrada académica de honor de la Real Academia Hispano Americana de Cádiz y en 1935 representa a la Biblioteca Nacional, junto con Miguel Artigas, en el XXVI Congreso Internacional Americanista celebrado en Sevilla.

Dejando aparte su trayectoria profesional e intelectual y centrándonos en su postura ideológica, Luisa tomó partido claramente por la izquierda, afiliándose a la FETE (Federación Española de Trabajadores de la Enseñanza, de UGT) en 1931.

${ }^{7}$ Santiago de Compostela: Tip. de El eco franciscano, 1930. Las publicaciones que enumeramos a continuación no pretenden ser una relación exhaustiva, solo un ejemplo de las más significativas en los distintos campos.

${ }^{8}$ Arquivos do Seminario de Estudos Galegos, 1932, pp. 141-217.

${ }^{9}$ Boletín de la Universidad de Santiago, año III, no 4 (dic. 1929-en. 1903), pp. 3-38; no 8 (dic. 1930-en. 1931), pp. 3-17.

${ }^{10}$ Gutenberg-Jahrburch, 1932, pp. 202-244.

${ }^{11} \mathrm{~N}^{\mathrm{o}} 7$ (1934). Aunque la revista se encuentra entre los fondos de la Biblioteca Nacional, no hemos podido localizar ningún ejemplar de este número. Curiosamente, tampoco se encuentra localizable en las bibliotecas argentinas, por lo menos hasta donde hemos podido indagar. Aprovechamos estas líneas para expresar nuestro agradecimiento a la bibliotecaria de Buenos Aires Verónica Fernández Rojo por la ayuda prestada.

${ }^{12}$ Anuario de Historia del Derecho Español , no 11 (1934), pp. 479-486.

${ }^{13}$ Gutenberg-Jahrburch, 1935, pp. 74-92.

${ }^{14}$ El ejemplar de la tesis figura entre los fondos de la Universidad Complutense y está accesible a través del catálogo Cisne (T3314). La autora publicó un reumen en el Boletín de la Universidad de Santiago de Compostela, año VII, na 24 (1935), pp. 75-96. 
Más adelante, en 1935, cotizará al Partido Comunista y formará parte de la Asociación de Amigos de la Unión Soviética. Durante la guerra se integrará en el Frente Popular de Funcionarios, constituido en 1936, y en 1937 en el Sindicato de Trabajadores de Archivos, Bibliotecas y Museos (STABYM), desde su fundación.

Nos imaginamos el ambiente que reinaba entre los funcionarios de la Biblioteca Nacional y las críticas que recibían personas como Luisa. Como la que sigue, extraída de la declaración del bibliotecario Antonio Sierra en el proceso de depuración al que, como era de esperar, fue sometida al finalizar la guerra y que veremos más adelante: "esta funcionaria comunista (...) tenía complacencia en exponer en las vitrinas, como jefe del Salón de Lectura, libros de ideas extremistas, procurando no se leyesen los derechistas que se iban publicando" ${ }^{\prime 15}$.

En 1933 fue designada para asistir al Certamen del Libro Español que se celebró en Buenos Aires con motivo de la Exposición del Libro Español en dicha ciudad y que tenía como objetivo dar a conocer las obras editadas en España, acabar con las campañas contrarias al libro español y denunciar las ediciones clandestinas, y constituyó un preludio de la política del libro que llevó a cabo posteriormente el Instituto del Libro Español en América ${ }^{16}$. En Buenos Aires coincidió con José Moreno Villa, por entonces director del Archivo del Palacio Real, que cuenta en su obra autobiográfica Vida en claro $^{17}$ los detalles de aquellos días pasados en compañía de Amado Alonso y otros intelectuales. Echamos de menos en la obra, de enorme interés y belleza por otra parte, una mención a Luisa, compañera de profesión del autor, que dio una conferencia sobre la organización y funcionamiento de la Biblioteca Nacional.

\section{EL FIN DE “AQUELLA ESPAÑA QUE TUVO LA OSADÍA DE CREER EN LA ESPERANZA"18: LUISA CUESTA, BIBLIOTECARIA EN TIEMPOS DE GUERRA}

Tras el golpe de estado del 18 de julio de 1936, el Ministerio de Instrucción Pública y Bellas Artes sustituye la Junta Facultativa por una Comisión Gestora del Cuerpo Facultativo de Archivos, Bibliotecas y Museos, presidida por Navarro Tomás, con Juan Vicens como secretario y con José Aniceto Tudela, Luisa Cuesta, Teresa Andrés, Francisco Rocher, Ricardo Martínez Llorente y Ramón Iglesia como vocales. Su principal función era reorganizar el Cuerpo y optimizar los

\footnotetext{
${ }^{15}$ Los documentos citados en este y en los apartados siguientes, proceden de los expedientes citados con anterioridad (véase la nota 3 de este artículo).

${ }^{16}$ MARTÍNEz Rus, Ana: La política del libro durante la II República: socialización de la lectura. Gijón: Trea, 2003, pp. 341-343.

${ }^{17}$ Madrid: Visor, 2006 (la primera edición fue publicada por el Colegio de México en 1944).

${ }^{18}$ Cita tomada de Manuel Talens, en "Antonio Machado: la pluma del escritor como pistola política”, Rebelión, 13-4-2007: http://www.rebelion.org/noticia.php?id=49636
} 
recursos de los que se disponía en beneficio de la cultura ${ }^{19}$, aunque es curioso leer la opinión que uno de los vocales, Martínez Llorente, expone después de la guerra como declarante en el expediente de depuración a Luisa anteriormente citado:

En esta comisión, desde el primer momento, se manifestaron dos tendencias que pudiéramos llamar radical o extremista y conservadora y moderada. La primera la defendían los Srs. Vicens, Iglesia y Teresa Andrés; la segunda la Srta. Cuesta, el Sr. Rocher y el que suscribe. Los Sres. Navarro Tomás y Tudela actuaban en lo que se pudiera llamar aunar voluntades. Por esta causa dicha Comisión Gestora no hizo nada práctico y por lo mismo fuimos eliminados de ella los citados Sres. Rocher, Srta. Cuesta y el que subscribe cuando en sustitución de ella se constituyó el Consejo de Archivos, Bibliotecas y Tesoro Artístico.

Efectivamente, la postura de Luisa Cuesta le trajo complicaciones desde un primer momento con sus propios compañeros, tanto de la FETE como de la Comisión Gestora, pues no siempre estaba de acuerdo, junto a Rocher, con las decisiones que ambas tomaron en determinados momentos. Son significativas dos anécdotas que ella misma cuenta: al cumplir el encargo de la FETE de acudir a un orfanato en Prosperidad y comprobar, una vez allí, que la finalidad era sustituir a los profesores que tenían ideas de derechas, protestó ante el sindicato alegando que se sentía engañada. La segunda anécdota remite a una sesión del Frente Popular de Funcionarios en la que defendió a su entonces director Miguel Artigas ante los ataques de los presentes, lo que, lógicamente, le granjeó la enemistad de muchos de sus colegas.

Enemistad que llegó a fructificar en tres denuncias de las que tenemos constancia: una realizada por Juan Vicens a la FETE por discrepar de sus orientaciones, otra al Director General de Bellas Artes por oponerse a que "se molestara a las compañeras del taller de costura" (reproducimos sus palabras, extraídas del expediente de depuración) y una tercera al presidente de la Junta del Tesoro Artístico por oponerse al traslado de la biblioteca de Artigas.

A raíz de la detención masiva de los funcionarios de la Biblioteca Nacional el 2 de octubre de 1936, provocada por los rumores de la existencia en ella de un núcleo de quintacolumnistas, se enfrentó a Teresa Andrés en una sesión del Frente Popular, en la que intercedió a favor de los compañeros detenidos. Después de eso

${ }^{19}$ La documentación emitida por la Comisión Gestora se encuentra en el Archivo de la Biblioteca Nacional. Véase el artículo de Enrique Pérez Boyero: "El archivo de la Biblioteca Nacional: fuentes documentales para el estudio de los archivos, bibliotecas y museos españoles durante la guerra civil", en Biblioteca en guerra, op. cit., pp. 169-196. Del mismo autor: "El Cuerpo Facultativo de Archiveros, Bibliotecarios y Arqueólogos y la protección y evacuación del patrimonio histórico en la España Republicana", en Patrimonio, Guerra Civil y Posguerra: congreso internacional. Madrid: Universidad Complutense, 2010, pp. 125-158. 
decidió marcharse a Guadalajara a casa de un hermano, pero fue detenida en la estación y conducida a la cárcel de Toreno, donde permaneció cinco días hasta que dicho hermano, secretario de la Diputación, hizo las gestiones necesarias para que fuera puesta en libertad.

Pero el asunto que más problemas le ocasionó fue su total desacuerdo con la decisión de impedir que los sacerdotes pudiesen ejercer cargos en el Cuerpo por el hecho de ser sacerdotes. La actitud de Luisa Cuesta podemos considerarla de simple compañerismo: una persona nada religiosa y sí comprometida socialmente, defiende a sus compañeros por el hecho de ser profesionales, independientemente de su condición religiosa. Está claro que Luisa tenía muchos problemas derivados de su afán de rectitud moral, y la acusación de "defensora de curas" que se le hizo junto a Rocher es cierta si tenemos en cuenta los testimonios de los compañeros que declaran a su favor en el proceso de depuración y que resumimos en el siguiente párrafo de Miguel Bordonau: "ella fue contribuyente voluntaria en los gastos del entierro del compañero y sacerdote asesinado don Santos Álvarez Molaguero, ella fue también quien ayudó eficazmente a poner a salvo al sacerdote y compañero D. Florentino Zamora, también avisó a los compañeros sacerdotes de la Biblioteca Nacional para que se escondiesen porque iban a detenerles..." Incluso fue a casa del sacerdote Pedro Longás con idéntica intención, mientras Julián Paz hacía lo mismo con Martín de la Torre.

De entre todos ellos, el padre Florentino Zamora protagonizó un episodio que merece reseñarse aquí y que tomamos de las palabras de Isabel Niño, de nuevo entresacadas del expediente de depuración ${ }^{20}$ :

Luisa y yo entramos solas en la cámara blindada, depósito de incunables, y escondidos entre las batas, sacamos platos, cubiertos, una bata negra, el breviario de nuestro compañero D. Florentino Zamora y una manta de Luisa. Unas cosas las escondimos en otras salas, entre los libros, y otras se las llevó Luisa a su casa. $\mathrm{Y}$ entonces me enteré que nuestro compañero D. Florentino Zamora (sacerdote) había estado escondido allí hasta dos días antes de nuestra detención y esto con conocimiento y anuencia de Tudela y Luisa y ella misma con Bordonau le llevaban comida.

Y Federico Navarro, en su testimonio, concreta:

... ella misma se prestó a entretener a los porteros para que el mencionado compañero pudiera salir sin ser visto y evitar su detención.

\footnotetext{
${ }^{20}$ De todas las declaraciones incluidas en el expediente, la más prolija y útil para conocer detalles de la actuación de Luisa Cuesta durante la guerra es, sin duda, la de Isabel Niño, de la que obtenemos abundante información.
} 
Si a todo esto le añadimos la protección a otra compañera de derechas, la preocupación por la familia de un bibliotecario asesinado y el testimonio a favor de otros detenidos, además de un enfrentamiento con Rodríguez Moñino cuando se trató de evacuar los fondos a Valencia... es lógico que Luisa no tuviera más que problemas con los que en principio consideraba "los suyos". Su compañera Isabel Niño aporta un ejemplo de la desconfianza que inspiraba cuando narra cómo Matilde López Serrano (bibliotecaria que, mientras trabajaba en la Junta Delegada del Tesoro Artístico de Madrid, actuaba como agente del Servicio de Información y Policía Militar, coordinador de la "quinta columna") tuvo que defenderla ante las autoridades "pues se la acusaba de mujer peligrosísima para el régimen y que favorecía a los facciosos".

En marzo de 1937 se disuelve la Comisión Gestora y se constituye la Comisión Delegada del Consejo Central de Archivos, Bibliotecas y Tesoro Artístico, de la que ya no formará parte Luisa Cuesta (aunque había tenido la ocasión de ejercer de directora en funciones poco antes, al hallarse en Valencia Navarro Tomás y Tudela). Sí la localizamos entre los miembros del equipo encargado de catalogar los libros incautados y depositados en la Biblioteca Nacional por la Junta de Incautaciones, cuya función era la salvaguarda del patrimonio bibliográfico.

Luisa participó activamente en las labores de salvamento y protección de las obras de arte, acudiendo personalmente a Guadalajara a comienzos de la guerra en compañía de Ramón Iglesia para controlar el vandalismo que tuvo lugar en los días siguientes a la entrada de las tropas leales en la ciudad. La labor de ambos bibliotecarios la detalla Luisa en un informe firmado el 18 de mayo de 1937 y dirigido al Consejo Central, en el que expone cómo Ramón Iglesia regresó a Madrid ante las dificultades que encontró en un primer momento, aunque posteriormente se continuó la labor, procediéndose a la incautación de los bienes recogidos en los pueblos y depositándolos en la Diputación. Sin embargo, Luisa denuncia la falta de medios para recoger todos los que necesitaban protección, que se hallaban en distintos archivos, bibliotecas de órdenes religiosas, conventos e iglesias ${ }^{21}$.

Antes de continuar, debemos hacer referencia al Decreto de 26 de septiembre de 1936 dictado por el Gobierno Republicano, según el cual se suspendían los derechos de todos los funcionarios públicos, que disponían del plazo de un mes, prorrogado posteriormente por otro más, para solicitar la readmisión. Para ello debían presentar una instancia acompañada de un cuestionario debidamente contestado y pruebas documentales de los méritos que se alegaban. La solicitud de readmisión de Luisa está firmada el 1 de mayo de $1937^{22}$ y el dictamen favorable el 23 de septiembre. Entre la documentación encontramos las pruebas de fidelidad al gobierno aducidas por la

\footnotetext{
21 "Informe de mi visita a Guadalajara para informar al Consejo Central de Archivos, Bibliotecas y Tesoros Artístico", Archivo B-N Junta 211/100.

${ }^{22}$ Ignoramos la razón de esta presentación fuera de plazo, que parece ser (según la documentación consultada) común a los demás funcionarios del Cuerpo Facultativo.
} 
bibliotecaria (cotización al PCE, pertenencia a la Asociación de Amigos de la URSS, a la FETE, al Frente Popular de Funcionarios, al STABYM) y en el dictamen, dentro del apartado de "actitud ante el movimiento sedicioso", la peculiar frase: "de ideología liberal, pero por razones patológicas es incongruente y derrotista". Aunque a primera vista resulta algo incomprensible, cobra sentido si tenemos en cuenta los problemas y enfrentamientos que había tenido con sus compañeros de la Gestora y de la FETE, a los que hemos aludido antes.

En noviembre de 1937, ante el cierre de los archivos, bibliotecas y museos de Madrid, se hicieron efectivos los traslados de los funcionarios, según la Orden Circular de 9 de septiembre, a los destinos encomendados y, en su defecto, a Valencia. Luisa fue destinada a la Delegación de Hacienda y Biblioteca Pública de Guadalajara. La extraordinaria labor profesional que la bibliotecaria realizó allí queda patente en la memoria que remite en 1939 al entonces Jefe del Servicio de Archivos, Bibliotecas y Registro de la Propiedad Intelectual Javier Lasso de la $\mathrm{Vega}^{23}$. En ella expone cómo la biblioteca se encontraba cerrada al público, con los fondos sin catalogar y "mezclados los manuscritos, incunables y demás libros preciosos con los corrientes". Ante esta situación, y para satisfacer las necesidades de la población mientras afrontaba la organización del centro, puso en marcha un servicio de préstamo que tuvo un enorme éxito y que se amplió a hospitales y prisiones. El fondo de la Biblioteca Provincial quedó perfectamente ordenado y catalogado, siendo objeto los aproximadamente 300 incunables y libros del XVI de una precatalogación pendiente de verificar con los índices y repertorios de la Biblioteca Nacional cuando fuera posible. Esta labor es aún más encomiable teniendo en cuenta las condiciones adversas en las que se desarrolló, acentuadas por la proximidad de los frentes.

\section{5 "QUE BORREN SUS YERROS PASADOS"24: EL EXPEDIENTE DE DEPURACIÓN DE LUISA CUESTA}

El 9 de febrero de 1939 se promulga la Ley de Responsabilidades Políticas, sobre la depuración de los empleados públicos. El siguiente párrafo extraído de su Preámbulo, de enorme cinismo al "confundir" a los sediciosos con los leales al gobierno oficial, resume el espíritu de dicha ley:

\footnotetext{
23 "Memoria de los trabajos efectuados en la Biblioteca de Guadalajara durante mi permanencia al frente de ella", firmada el 31 de mayo de 1939. ABUCM, Informe sobre bibliotecas periodo rojo (1938-1939), caja 4.

24 "Borrar los yerros pasados" mediante el cumplimiento de sanciones justas era una de las finalidades de la Ley de Responsabilidades Políticas de 9 de febrero de 1939, de manera que se favoreciera la convivencia entre los que contribuyeron a "forjar la subversión roja" y los españoles "que en haz apretado han salvado nuestro país y nuestra civilización", tal como queda expresado en el Preámbulo a la citada ley.
} 
Es el deseo del Gobierno llevar a cabo esta depuración con la misma rapidez y dentro de normas flexibles que permitan reintegrarse rápidamente a sus puestos a aquellos funcionarios que lo merecen por sus antecedentes y conducta, y al mismo tiempo imponer sanciones adecuadas, según los casos, a los que, incumpliendo sus deberes, contribuyeron a la subversión y prestaron asistencia no excusable a quienes por la violencia se apoderaron, fuera de toda norma legal, de los puestos de mando de la Administración.

Con fecha de 14 de abril Luisa tiene que realizar una declaración jurada, trámite obligatorio por el cual el funcionario debía cumplimentar un cuestionario con todos sus datos personales y laborales y responder a preguntas tales como si prestó adhesión al "movimiento nacional", al "gobierno marxista", si fue por coacción, a qué partidos o entidades estuvo afiliado, si perteneció a la masonería, así como citar los testigos y documentos que pudieran, a su juicio, dar fe de lo que declarase.

Una vez cumplimentada, un instructor comprobaba los hechos y su dictamen podía dar lugar a la admisión en el Cuerpo o a la incoación de un expediente, tras ser aceptada la propuesta por el Jefe del Servicio Nacional del Cuerpo y por el ministro correspondiente. El funcionario expedientado podía presentar, en un plazo de ocho días, un pliego de cargos y los documentos exculpatorios necesarios. Hasta la resolución del expediente, quedaban suspensos en sus cargos mientras se dictaminara o no la sanción correspondiente, que podía ser: traslado forzoso, con prohibición de solicitar cargos vacantes durante uno a cinco años; postergación, desde uno a cinco años; inhabilitación para el desempeño de puestos de mando o de confianza y separación definitiva del servicio ${ }^{25}$.

Luisa reconoce todo lo que ya hemos visto a lo largo de este artículo y cita como testigos a Pedro Longás, Amalio Huarte y Julián Paz, de la Biblioteca Nacional; al sacerdote y profesor de Literatura del Instituto de Guadalajara y a Estanislao Serrano, empleado de Hacienda de la misma ciudad. Además, numerosos compañeros y compañeras declaran espontáneamente, destacando entre los que la defienden Ramón Paz, el sacerdote Martín de la Torre, los hermanos Valentín y Francisco Sambricio, José María Lacarra, Miguel Bordonau y, especialmente, Isabel Niño, que llena nada más y nada menos que ocho folios por ambas caras en los que narra con todo lujo de detalles la actuación de Luisa. "Cuanto más medito en la actuación de compañeros como Luisa y Tudela, más me convenzo de su verdadero heroísmo", declara después de afirmar que en un principio su trato con ella era más bien distante. Es en la declaración de Isabel Niño en la que encontramos ampliamente descrito el episodio de la ocultación del padre Zamora, del que echamos en falta una declaración a favor de la persona que le había salvado la vida. Por supuesto, muchos de los declarantes no la defienden en absoluto,

${ }^{25}$ Información extraída de YOLANDA BLASCO Gil, "Soporte jurídico de las depuraciones", en CUESTA, Josefina (dir.): La depuración de funcionarios bajo la dictadura franquista (19361975). Madrid: Fundación Francisco Largo Caballero, 2009, p. 38. 
como es el caso de Río y Rico, que afirma escuetamente "que aunque salvó a algún compañero aceptaba cargos de los marxistas y por orden de ellos fue a Guadalajara a incautarse de las bibliotecas de las órdenes religiosas allí residentes, acompañando a Ramón Iglesia". Tal como lo cuenta, casi da a entender que Luisa formaba parte de las masas incontroladas, cuando hemos visto que su trabajo consistió precisamente en lo contrario, en colaborar con la protección del patrimonio impulsada por el gobierno republicano. Y leemos también afirmaciones que rayan el absurdo, aunque hechas con la mejor intención, como la de José María Castrillo, quien alega en su defensa que "conservaba junto con el carnet sindical, creo que comunista, el rosario de su madre". Lógicamente, e independientemente de estas simplezas, los testigos se agarraban a lo que más podía influir en la posible opinión positiva del juez, transmitiéndonos un retrato de una mujer de la que, a pesar de figurar entre las "hordas marxistas", podía salvarse su alma, cristiana en el fondo... Qué mejor argumento para un juez del bando vencedor y qué lejos se encontraba todo esto de la verdadera personalidad de Luisa Cuesta.

$\mathrm{Si}$ en un principio parecían prevalecer las declaraciones en las que primaba su compañerismo frente a su actuación al lado del gobierno republicano, lo que auguraba un desarrollo más bien positivo del expediente, pronto se añadieron al mismo unas cartas del ingeniero industrial Leopoldo de Llera de la Gala a Javier Lasso de la Vega, que este hizo llegar al juez instructor del Cuerpo de Archiveros, Bibliotecarios y Arqueólogos, Miguel Gómez del Campillo.

Para entender el espíritu de venganza y revanchismo que supuran las cartas (fechadas el 27 de junio y el 15 de julio de 1939) hay que remontarse al desgraciado suceso que tuvo lugar el verano de 1936, en el que la familia Gala de la Llera, del pueblo de Granja de Torrehermosa (Badajoz), fue asesinada, al parecer, por milicianos del Frente Popular.

Llera coincidió con Luisa cuando ambos se alojaban en la pensión Excelsior (calle Eduardo Dato, 6) durante la guerra, estando él oculto allí después de una estancia en la cárcel. Acostumbradas como estamos hasta ahora a leer testimonios llenos de buena voluntad hacia Luisa, en los que se prima su faceta de compañera que no duda en arriesgarse por ayudar a sus compañeros sacerdotes (hecho loable, sin duda), agradecemos, sin embargo, poder imaginarnos a la bibliotecaria indignada ante los bárbaros acontecimientos que le tocó vivir. Así, Llera, que manifiesta su obligación de denunciarla como deber que tiene que cumplir "para nuestros mártires y caídos", la retrata de la siguiente manera: "Para esta mujer, nuestros generales eran unos canallas, los fascistas hacían más canalladas que los rojos, los libros aquellos que se publicaron en la zona roja, como Un año con Queipo y otros, decían la verdad escueta; en fin, no quiero cansarte con otros detalles indignantes que acreditan su colorido político".

Llera, que sabe de la declaración jurada de Luisa y de los numerosos testimonios a su favor, se siente obligado a denunciarla por considerar "a todos los frentepopulistas igualmente responsables de esta inmensa tragedia [la matanza de su familia en la Granja de Torrehermosa]". No sabemos cuántos funcionarios fueron víctimas de sus 
denuncias, pero tampoco entendemos por qué esa inquina contra Luisa, de la que dice que "no ha de salirse con la suya". Lo que sí se desprende del texto es un retrato no muy favorecido del denunciante, pues, al mismo tiempo que narra a Lasso de la Vega los "terribles insultos" que sobre su persona vertió Luisa una vez perdida la guerra, reconoce que él no fue capaz de defenderle porque "no sabía el terreno que pisaba". El leal compañero le recuerda a la supuesta víctima de la lengua viperina de Luisa que "lo importante es que no incurramos en la candidez de incrustar a sabiendas en nuestros organismos e instituciones a esos vampiros que, poco o mucho, a todos les corresponde una parte alícuota de culpa en la tragedia". Lamentablemente para él, la labor depuradora que se está llevando a cabo no tiene el éxito que se merece y se encuentra "desilusionado": "Hoy he escrito al General Queipo a ver si se puede evitar que paseen tranquilamente por las calles los centenares de criminales que aquí existen. Veremos". Dada la feroz represión llevada a cabo por Queipo de Llano en Sevilla, estamos seguras de que el General no defraudó las expectativas de don Leopoldo.

El 27 de noviembre se formula un pliego de cargos contra Luisa en el que los imputados son los mismos que ella había alegado a su favor en la solicitud de reingreso en el cuerpo de funcionarios en 1937: cotizante del Partido Comunista, miembro de la FETE, del Frente Popular de funcionarios, de la Comisión Gestora, de la Unión de Amigos de la Unión Soviética y del STABYM, a los que se unen las acusaciones de "extremada izquierdista", de "hablar violentamente contra el Glorioso Movimiento Nacional y su significación" y de haber sido "persona de la confianza oficial de los dirigentes rojos".

Luisa responde a todos los cargos como buenamente puede, justificando sus diversas sindicaciones y aportaciones como algo obligado por las circunstancias y exponiendo todas las situaciones que vivió y que hemos visto antes como prueba de que no tenía la confianza del gobierno oficial e incluso tuvo que hacer frente a tres denuncias y a una estancia en la cárcel. Hay que comprender la situación en la que se encontraba cuando leemos cosas como esta: "durante la guerra y ante los graves errores que aquí se cometían en nombre de ella deseaba como todos los españoles que vivíamos en esta zona una situación mejor y esto parecía estar del lado de los nacionales. (...) Deseaba la cesación de las persecuciones y la cordialidad lograda en una verdadera España nacional y patriótica". Por lo menos, nos encontramos también con cierta osadía cuando defiende la actuación de la Comisión Gestora de la siguiente manera: “(...) Quisiera llevar al convencimiento del Sr. Juez que la Gestora, lejos de ser algo dañino para el Cuerpo, fue un pararrayos que evitó muchos males que hubiera sufrido de no existir él (...) De no haberse creado la Gestora, la Nacional y el Cuerpo hubieran sufrido la injerencia de elementos extraños y desde luego de categoría espiritual mucho más baja que la que este organismo representó". Tal como estaban las cosas y teniendo en cuenta a lo que se enfrentaba, hay que valorarlo como un gesto valiente.

El juez instructor propone al Director General de Archivos y Bibliotecas la siguiente conclusión del expediente, que reproducimos: 
Por todos estos cargos debiera separarse a esta Srta. definitivamente del servicio; pero teniendo en cuenta su verdadera y mejor defensa que es la calificación de los rojos como de ideología liberal, pero por razones patológicas, incongruente y derrotista, y el testimonio favorable a su conducta de muchos funcionarios, podría atenuarse esta pena; mas por si esas razones patológicas la obligan a seguir siendo incongruente y derrotista hacia el nuevo Estado y su significación, el que suscribe tiene el honor de proponer la imposición de las siguientes sanciones (...): traslado forzoso con prohibición de solicitar cargos vacantes durante tres años; postergación durante tres años; inhabilitación para el desempeño de puestos de mando o confianza.

Finalmente, el Director General resuelve imponerle la sanción de traslado forzoso durante un año.

Luisa fue destinada al Archivo de la Delegación de Hacienda de Ciudad Real, con la misión de encargarse además de la Biblioteca Pública de dicha ciudad. Cesó en la Biblioteca Nacional en enero de 1940.

\section{EL CORAJE DE UNA BIBLIOTECARIA SUPUESTAMENTE DERROTISTA: DE VUELTA A LA BIBLIOTECA NACIONAL}

Tuvieron que pasar unos años antes de que volviera a ocupar un puesto de trabajo en la Nacional. Tras Ciudad Real estuvo destinada, ya en Madrid, en la biblioteca de la Escuela de Peritos Industriales. Mientras, oposita en 1941 a cátedras de instituto de Geografía e Historia, examinándose por libre en el Instituto Lope de Vega de Madrid. Y entre 1942 y 1955 compaginará su trabajo de bibliotecaria con el de profesora en el Instituto Cervantes, dentro de la categoría de "ayudante interino y gratuito", en la cátedra de Geografía e Historia. Ya antes lo había hecho en el Instituto Lagasca, convertido después de la guerra en la Escuela-Fábrica de Cerámica de Madrid y Escuela Municipal de Artes Industriales, pero no hemos conseguido documentar el periodo exacto.

En 1944 se presenta al Premio de Bibliografía de la Biblioteca Nacional, estando destinada en la Biblioteca de Peritos Industriales, que obtiene por su obra La imprenta en Salamanca y que la convierte en la primera mujer que gana este concurso. El Patronato de la Biblioteca acordó publicarla en 1953, pero la obra no se publicó hasta 1960 y solo en parte: La imprenta en Salamanca: avance al estudio de la tipografía salmantina $(1484-1944)^{26}$. A pesar de las fechas indicadas,

\footnotetext{
${ }^{26}$ Salamanca: Diputación Provincial, 1960. La obra se interrumpe en la página 160 y faltan los índices, siendo relativo a 1541 el último registro bibliográfico incluido. La misma Diputación, junto con la Universidad de Salamanca, realizó una edición facsímil en 1981, con nota de Antonio Lucas Verdú y Manuel Peláez del Rosal.
} 
solamente incluye la introducción y los impresos publicados hasta 1541, pues la impresión se interrumpió sin que se conozca la causa. Posteriormente, según Juan Delgado $^{27}$, se intentó publicar hacia 1976-1977, pero tampoco llegó a finalizarse la impresión, a pesar de disponerse ya de las galeradas.

El 6 de octubre de 1945 consigue, por fin, el traslado a la Biblioteca Nacional, y al año siguiente vuelve a presentarse al mismo concurso, esta vez con Justo García Morales, con la Bibliografia de la imprenta en Burgos. El premio les es otorgado, aunque el dictamen no tiene lugar hasta 1949, pero también la obra volverá a quedar inédita. Hecho inexplicable, pues se había pedido a los autores que la corrigieran con vistas a su impresión y se les había costeado el traslado a Burgos durante diez días para que completaran su trabajo. No nos detendremos a analizar ambos repertorios, incomprensiblemente inéditos en su momento, pues ya se encarga de ello Juan Delgado, pero sí indicaremos que las ciudades de Salamanca y Burgos cuentan ya con sendas tipobibliografías cuyos autores, Lorenzo Ruiz Fidalgo y Mercedes Fernández Valladares, han utilizado ese primer material elaborado por Luisa Cuesta, como mencionan en sus respectivas introducciones ${ }^{28}$.

Luisa va a aprovechar todas las oportunidades que se le brinden para continuar ampliando sus conocimientos, dentro de la inquietud y curiosidad que hemos visto que marcó toda su trayectoria profesional. Así, los veranos de 1946, 1948 y 1949 los pasa en Portugal (acompañada de su hermana Modesta, licenciada en Farmacia y funcionaria también de la Biblioteca Nacional con la categoría de auxiliar), estudiando el funcionamiento de distintas bibliotecas: las de Coimbra y Lisboa pensionada por la Junta de Relaciones Culturales; las de Oporto, Mafra, Lisboa y Villaviciosa, pensionada por el Instituto Nicolás Antonio del CSIC; y las de Braga y Oporto, invitada por el Instituto de Alta Cultura de Portugal. Estas escapadas anuales contrarrestarían sin duda el ambiente sórdido y falto de alicientes que impregnaba la vida cultural española de la posguerra y no es difícil deducir que una bibliotecaria con la trayectoria de Luisa Cuesta necesitaba respirar otro tipo de aire. Es significativo que solicite más adelante, en 1956 y a solo seis años de su jubilación, una plaza nada más y nada menos que en Bogotá.

En 1949 es nombrada jefa de la Sección de Hispanoamérica, donde permaneció hasta su jubilación. Durante estos años no deja de publicar, no solamente los resultados de sus investigaciones en el extranjero, sino sobre otros aspectos. Encontramos numerosos artículos en la Revista de Archivos, Bibliotecas y Museos, uno curiosamente con Florentino Zamora, el protagonista del episodio novelesco del

${ }^{27}$ Un siglo de bibliografía en España: los concursos bibliográficos de la Biblioteca Nacional (1857-1953). Madrid: Ollero y Ramos, 2001, pp. 335-344.

${ }^{28}$ Véanse las obras de Lorenzo RUIZ FIDALGO: La imprenta en Salamanca (1501-1600). Madrid: Arco Libros, 1994 y Mercedes FERNÁNDEZ VALLADARES: La imprenta en Burgos (1501-1600). Madrid: Arco Libros, 2005. 
que hemos tratado anteriormente, sobre "Los secretarios de Carlos V",29 (para el que se le concedió una beca en 1957 que le permitió trabajar en los archivos de Viena y Bélgica). Su trayectoria como licenciada en Derecho puede observarse en artículos como "Formulario notarial y castellano del siglo XV",30 o "Pleitos cortesanos en la Biblioteca Nacional"31; los resultados de su trabajo como jefa de la Sección de Hispanoamérica en su participación en el Catálogo de la Exposición de libros y mapas sobre la independencia de América ${ }^{32}$ organizada por el Instituto de Cultura Hispánica en colaboración con la Biblioteca Nacional de Madrid y en el Catálogo de obras iberoamericanas y filipinas de la Biblioteca Nacional de Madrid ${ }^{33}$, obra que sigue siendo de gran utilidad hoy día. La línea de investigación sobre Latinoamérica está presente en artículos como "La petición de Francisco de Orellana en 1543 y pareceres de los del Consejo"34, "También los conquistadores se quejaban"35, "Testamento de don Pedro Gasca, pacificador del Perú, y la apertura del mismo"36. Y su interés por obras sobre la historia de la imprenta o sobre distintos aspectos de la técnica impresora (ya manifestado en los dos premios de bibliografía recibidos) en "La edición de las obras de El Tostado, empresa de la corona española"37, "La imprenta en Burgos a través de su historia" 38 , "Los tipógrafos extranjeros en la imprenta burgalesa del alemán Fadrique de Basilea al italiano Juan Bautista Varesio"39, "Las impresiones españolas de Erasmo en la época imperial"40, "Algunos datos sobre la impresión de bulas en España"41, "La imprenta en el libro en la América hispana colonial",2, "Una escuela de grabadores de letra en la Salamanca del siglo XVIII"43, etc., muchos de ellos publicados en revistas prestigiosas como la Revista de Indias o GutenbergJahrbuch, aparte de la Revista de Archivos, Bibliotecas y Museos y el Boletín de la Dirección General de Archivos y Bibliotecas.

Habiendo llegado a este punto, podemos plantearnos la siguiente reflexión, después de haber conocido la vida y trayectoria profesional de Luisa Cuesta: debemos, sin

${ }^{29}$ 1-6-1958, pp. 415-448.

${ }^{30}$ Madrid: Instituto Nacional de Estudios Jurídicos, 1947.

${ }^{31}$ En colaboración con Jaime Delgado. Revista de Indias, vol. IX, no 31- 32 (1948), pp. 247-296.

${ }^{32}$ Madrid: [Biblioteca Nacional], 1949.

${ }^{33}$ Madrid: Dirección General de Archivos y Bibliotecas, 1953

${ }^{34}$ Revista de Indias, vol. XII, ${ }^{\circ} 49$ (1952), pp. 571-577.

${ }^{35}$ Ibidem, vol. XIII, no 51 (1953), pp. 117-118.

${ }^{36}$ Ibidem, vol. XIII, no 51 (1953), pp. 119-122.

${ }^{37}$ Revista de Archivos, Bibliotecas y Museos, año IV, t. LVI, no 2 (1950), pp. 321-334.

${ }^{38}$ Gutenberg-Jahrbuch, 1943, pp. 83-99.

${ }^{39}$ Ibidem, , 1952, pp. 67-74.

${ }^{40}$ Ibídem, 1950, pp. 203-208.

${ }^{41}$ Ibidem, 1955, pp. 86-92.

${ }^{42}$ Ibidem, 1957, pp. 160-167.

${ }^{43}$ Ibidem, 1953, pp. 129-132. 
ninguna duda, asignarle el adjetivo "moderna" que autoras como Mercedes Gómez Blesa o Shirley Mangini ${ }^{44}$ aplican a las mujeres universitarias del primer tercio del siglo XX que, rechazando el papel tradicional de "ángel del hogar", alcanzaron una independencia económica y una altura intelectual y personal a prueba de los insultos y prejuicios de algunos de los intelectuales del momento, de entre los cuales reproducimos la opinión incalificable de Ortega y Gasset: "El hombre inteligente siente un poco de repugnancia por la mujer talentuda", pues "la mujer demasiado racional le huele a hombre" ${ }^{45}$. Sobran los comentarios.

Luisa fue una "moderna" de pleno derecho: por sus estudios, investigaciones, profesiones, independencia económica, viajes al extranjero, conocimiento de idiomas, implicación social y política... Porque fue pionera como profesora universitaria, siendo una de las primeras en la Universidad de Valladolid y, posteriormente, en la de Santiago de Compostela. Y porque se sentía feminista, como lo refleja en algunas de sus publicaciones.

El final de su carrera laboral fue parejo, desgraciadamente, al de su vida: se jubiló el 19 de agosto de 1962, habiendo cumplido la edad reglamentaria, y falleció el 1 de septiembre en Madrid. Como leemos en la necrológica publicada en el Boletín de la Dirección General de Archivos y Bibliotecas ${ }^{46}$, "aun cuando en los últimos meses fuera ostensible en lo físico la grave crisis de su salud, el ánimo contrarrestaba o al menos encubría la acción destructora de la enfermedad (...) Seguía acudiendo a su Sección de Hispanoamérica y pasando en ella largas horas entre cantidades de fichas". Incluso tenía preparada una semblanza del bibliotecario José Martínez Planells, compañero suyo de oposición recién jubilado, que se publicó póstumamente en el mismo número de la revista y en la que Luisa habla de él en los siguientes términos, que podríamos hacer extensibles, sin duda, a ella misma: "Humildad, trabajo. Toda una vida consagrada al servicio de los libros".

Terminan, pues, al mismo tiempo, la trayectoria profesional y vital de una persona que no se caracterizó por sus grandes hazañas, pero dio muestras de un gran tesón, coraje y constancia desde sus primeros pasos en un pueblo de Valladolid y de una enorme coherencia personal a lo largo de su vida. Todo ello, junto a su labor como bibliotecaria, callada y discreta pero tenaz, la hacen merecedora de este recuerdo.

${ }^{44}$ Véanse las obras de GómEz BLESA, Mercedes: Modernas y vanguardistas: mujer y democracia en la II República. Madrid: Ediciones del Laberinto, 2009, y MANGINI GonZÁLEZ, Shirley: Las modernas de Madrid: las grandes intelectuales españolas de la vanguardia. Barcelona, Península, 2001. Además: Ni tontas ni locas: las intelectuales en el Madrid del primer tercio del siglo XX. Coordinación, Paloma AlCAlÁ CortiJO, Capi Corrales RODRIGÁÑEZ y Julia LóPEZ GIRALDEZ. Madrid: FECYT, 2009.

${ }^{45}$ Citado en Modernas y vanguardistas ..., op. cit., p. 157.

${ }^{46} \mathrm{~N}^{\mathrm{o}} 67$ (1-9-1962), p. 23. 